\title{
Failure rate of cemented and uncemented total hip replacements: register study of combined Nordic database of four nations
}

\author{
(c) (1) (8) OPEN ACCESS
}

\begin{abstract}
Keijo T Mäkelä associate professor ${ }^{1}$, Markus Matilainen statistician ${ }^{2}$, Pekka Pulkkinen statistician ${ }^{3}$, Anne M Fenstad statistician ${ }^{4}$, Leif Havelin professor ${ }^{45}$, Lars Engesaeter professor ${ }^{45}$, Ove Furnes professor $^{45}$, Alma B Pedersen clinical associate professor ${ }^{6}$, Søren Overgaard professor ${ }^{78}$, Johan Kärrholm professor ${ }^{9}$, Henrik Malchau professor ${ }^{9}{ }^{10}$, Göran Garellick associate professor ${ }^{11}$, Jonas Ranstam professor ${ }^{12}$, Antti Eskelinen associate professor ${ }^{13}$

'Department of Orthopaedics and Traumatology, Turku University Hospital, Rauhankatu 24 D 32, Turku, Fl-20100, Finland; ${ }^{2}$ Department of Biostatistics, Turku University, Finland; ${ }^{3} \mathrm{Hjelt}$ Institute, Helsinki University, Helsinki, Finland; ${ }^{4}$ The Norwegian Arthroplasty Register, Department of Orthopaedic Surgery, Haukeland University Hospital, Bergen, Norway; ${ }^{5}$ Department of Clinical Medicine, University of Bergen, Bergen, Norway; ${ }^{6}$ Competence Centre for Clinical Epidemiology and Biostatistics, North, Department of Clinical Epidemiology, Aarhus University Hospital; ${ }^{7}$ Department of Orthopaedic Surgery, Traumatology and Clinical Institute, Odense University Hospital, Odense, Denmark; ${ }^{8}$ Danish Hip Arthroplasty Register, Department of Clinical Epidemiology, Aarhus University Hospital, Aarhus, Denmark; ${ }^{9}$ The Swedish Hip Arthroplasty Register, Department of Orthopaedics, Institute of Surgical Sciences, Sahlgrenska University Hospital, University of Gothenburg, Mölndal, Sweden; ${ }^{10}$ Orthopaedic Department, Massachusetts General Hospital/ Harvard Medical School, Boston, Massachusetts, US; ${ }^{11}$ The Swedish Hip Arthroplasty Register, Department of Orthopaedics, Institute of Surgical Sciences, Sahlgrenska University Hospital, University of Gothenburg, Mölndal, Sweden; ${ }^{12}$ Swedish National Competence Center Musculoskeletal Disorders, Skåne University Hospital, Lund, Sweden; ${ }^{13}$ The Coxa Hospital for Joint Replacement, Tampere, Finland
\end{abstract}

\begin{abstract}
Objective To assess the failure rate of cemented, uncemented, hybrid, and reverse hybrid total hip replacements in patients aged 55 years or older.

Design Register study.

Setting Nordic Arthroplasty Register Association database (combined data from Sweden, Norway, Denmark, and Finland).

Participants 347899 total hip replacements performed during 1995-2011.

Main outcome measures Probability of implant survival (Kaplan-Meier analysis) along with implant survival with revision for any reason as endpoint (Cox multiple regression) adjusted for age, sex, and diagnosis in age groups 55-64, 65-74, and 75 years or older.

Results The proportion of total hip replacements using uncemented implants increased rapidly towards the end of the study period. The 10 year survival of cemented implants in patients aged 65 to 74 and 75 or older $(93.8 \%, 95 \%$ confidence interval $93.6 \%$ to $94.0 \%$ and $95.9 \%$,
\end{abstract}

$95.8 \%$ to $96.1 \%$, respectively) was higher than that of uncemented (92.9\%, $92.3 \%$ to $93.4 \%$ and $93.0 \%, 91.8 \%$ to $94.0 \%$ ), hybrid $(91.6 \%$, $90.9 \%$ to $92.2 \%$ and $93.9 \%, 93.1 \%$ to $94.5 \%$ ), and reverse hybrid $(90.7 \%$, $87.3 \%$ to $93.2 \%$ and $93.2 \%, 90.7 \%$ to $95.1 \%$ ) implants. The survival of cemented $(92.2 \%, 91.8 \%$ to $92.5 \%)$ and uncemented $(91.8 \%, 91.3 \%$ to $92.2 \%$ ) implants in patients aged 55 to 64 was similar. During the first six months the risk of revision with cemented implants was lower than with all other types of fixation in all age groups.

Conclusion The survival of cemented implants for total hip replacement was higher than that of uncemented implants in patients aged 65 years or older. The increased use of uncemented implants in this age group is not supported by these data. However, because our dataset includes only basic information common to all national registers there is potential for residual confounding.

\section{Introduction}

Observational studies are efficient in assessing data on the survival of implants used for total hip replacements. The role 
of single, randomised controlled studies should not be over-emphasised in clinical decision making. ${ }^{12}$ Arthroplasty registers in Nordic countries have existed for a long time..$^{3-6}$ The Nordic Arthroplasty Register Association was established in 2007 by Sweden, Norway, and Denmark to improve the quality of hip and knee arthroplasty through collaboration of research. ${ }^{7}$ After Finland joined the association in 2010 the total population of the countries involved was 25.5 million. By conducting multinational register studies, comprehensive patient populations can be studied in high numbers thereby improving statistical precision. The number of hip replacements recorded in the Nordic Arthroplasty Register Association database (536 962) covering 1995 to 2011 is comparable to that of the National Joint Registry of England and Wales (458 568, covering 2003 to 2011) $)^{8}$ and the Australian Register (223 339, covering September 1999 to 2011). ${ }^{9}$ However, the follow-up time in the Nordic arthroplasty database is longer, which can be expected to have an influence on the outcome in terms of increased incidence of long term complications, such as loosening of implants.

Register based studies as well as systematic reviews have documented a better overall survival rate of cemented compared with uncemented implants for total hip replacements based on data from national arthroplasty registers. ${ }^{7-15}$ However, Nordic orthopaedic surgeons have followed the trend of an increased use of uncemented implants, similar to colleagues in western European countries, ${ }^{8}$ Australia, ${ }^{9}$ and the United States. ${ }^{15} 16$

Based on information from the Nordic Arthroplasty Register Association database, we assessed the survival of cemented, uncemented, hybrid (uncemented cup with cemented stem), and reverse hybrid (cemented cup with uncemented stem) implants for total hip replacements in patients aged 55 years or older.

\section{Methods}

\section{Sources of data}

The hip arthroplasty registers of Sweden and Denmark and the arthroplasty registries of Norway and Finland participated in the present study. From 1995 all four registers have used individual based registration of operations and patients. Therefore the data include total hip replacements performed during 1995-2011. A minimal dataset was created by the Nordic Arthroplasty Register Association to contain data that all four registers could deliver. ${ }^{7}$ The database includes information on the vital status of patients, enabling the survival of implants to be analysed.

Within each national register we performed selection and transformation of the datasets to equal the minimal dataset and deidentified the patients, which included deletion of their national civil registration numbers. We then merged the anonymised data into a common database. We treated the data with full confidentially, according to the rules of the respective countries. This included access to the common database, which was limited to the authors of the present paper. It is not possible to identify patients at an individual level, either in this paper or in the database. The quality of data in the Nordic registries is high. ${ }^{17-21}$

\section{Inclusion and exclusion criteria}

We included patients aged 55 years or older with a stemmed implant for total hip replacement (the results of younger patients will be analysed in a separate study). Overall, the Nordic Arthroplasty Register Association database contained data on 536962 hip replacements. If a patient had both hips replaced, we included data for only the first owing to potential bias of bilaterality. ${ }^{22}$ We also wanted to ensure that the analyses were not biased by potential errors in recording laterality. In total we excluded 3227 hip resurfacings, 88723 hip replacements owing to bilaterality, 38 procedures that were not primary operations, and 49424 owing to young age ( $<55$ years). We also excluded three patients aged more than 100 years because of suspected coding errors and 1694 hip replacements because the type of fixation was not mentioned. We excluded 20 hip replacements because of ambiguity over the laterality of the first operation, 45208 because the procedure was undertaken for hip fracture, and 726 owing to a missing diagnosis. Altogether we included 347899 total hip replacements: 232603 using cemented implants, 71454 uncemented, 28215 hybrid (uncemented cup with cemented stem), and 15627 reverse hybrid (cemented cup with uncemented stem).

\section{Statistical analysis}

We assessed the descriptive statistics of participants. We used Kaplan-Meier survival analysis to assess the probability of implant survival at 10 and 15 years. We determined survival data only when at least 100 total hip replacements were at risk. Patients were followed from the date of primary total hip replacement and censored at death or outcome, whichever came first. Outcome was defined as removal or exchange of at least one of the components, including liner exchanges of uncemented cups, for any reason. We used a Cox multiple regression model for different age groups to assess implant survival and hazard ratio of any revision as endpoint, with $95 \%$ confidence intervals and adjustment for age and diagnosis. Because none of the variables used for adjustment fulfilled the proportional hazard assumption for the whole study period, we stratified the model by sex and diagnosis. As type of fixation did not fulfill the proportional hazards assumption, we also split the follow-up period into one year intervals, except the first year, which we divided into two periods. We presented implant survival data for three age groups: 55-64, 65-74, and 75 years or older. These age groups were chosen to allow comparison of our results and data derived from other national registers using the same age groups. ${ }^{8}$ The Wald test was used to calculate the $\mathrm{P}$ values for data obtained from the Cox multiple regression analyses. We considered differences between groups to be statistically significant if the $\mathrm{P}$ values were less than 0.05 in a two tailed test.

To assess the time period effect we performed Kaplan-Meier analyses separately for total hip replacements during 1995-99, 2000-05, and 2006-11.

\section{Results}

The mean follow-up time for total hip replacements was 7.0 (range 0-17) years for cemented total hip replacements, 4.9 (0-17) for uncemented, 7.5 (0-17) for hybrid, and 3.4 (0-16.9) for reverse hybrid. The proportion of men was $39.4 \%$ (table $1 \Downarrow$ ). The proportion of total hip replacements using uncemented implants increased rapidly towards the end of the study period (fig $1 \Downarrow$ ). Of all total hip replacements, the proportion in 1995 and 2011 using, respectively, uncemented implants was $9.6 \%$ (1641/17 080) and 39.4\% (9328/23 693), hybrid implants was $9.2 \%(1563 / 17080)$ and $4.7 \%$ (1119/23 693), and reverse hybrid implants was $0.2 \%$ (40/17 080) and 12.3\% (2921/23 693).

Table $2 \Downarrow$ and figure $2 \Downarrow$ show unadjusted Kaplan-Meier survival curves with $95 \%$ confidence intervals for implants at 10 and 15 years by fixation type and age group. 
Table $3 \Downarrow$ presents the reasons for revision during the first six months postoperatively. Periprosthetic fractures were a more common reason for revision among uncemented total hip replacements $(27 \%$ (333/1213) of all revisions) than among cemented total hip replacements (4\% (57/1535) of all revisions).

Supplementary appendix table 1 and figure $3 \Downarrow$ present by age group the adjusted hazard ratios, $95 \%$ confidence intervals, and $\mathrm{P}$ values for uncemented, hybrid, and reverse hybrid total hip replacements, with cemented total hip replacement as the reference group.

\section{$\mathbf{1 0}$ year implant survival by age group}

55-64 years-The 10 year survival of cemented implants $(92.2 \%$, $95 \%$ confidence interval $91.8 \%$ to $92.5 \%$ ) was similar to that of uncemented and reverse hybrid implants $(91.8 \%, 91.3 \%$ to $92.2 \%$ and $92.4 \%, 90.9 \%$ to $93.7 \%$, respectively). The 10 year survival of hybrid implants $(90.0 \%, 89.2 \%$ to $90.7 \%)$ was inferior to that of cemented implants (table 2 and fig 2).

65-74 years-The 10 year survival of cemented implants (93.8\%, $93.6 \%$ to $94.0 \%$ ) was higher than that of uncemented, hybrid, and reverse hybrid implants $(92.9 \%, 92.3 \%$ to $93.4 \%, 91.6$, $90.9 \%$ to $92.2 \%$, and $90.7 \%, 87.3 \%$ to $93.2 \%$, respectively) (table 2 and fig 2).

$\geq 75$ years - The 10 year survival of cemented implants $(95.9 \%$, $95.8 \%$ to $96.1 \%$ ) was higher than that of uncemented and hybrid implants $(93.0 \%, 91.8 \%$ to $94.0 \%$ and $93.9 \%, 93.1 \%$ to $94.5 \%$, respectively) (table 2 and fig 2 ).

During the first six postoperative months the risk of revision for cemented implants was lower than that for each of the other three types of fixation in all age groups studied (see supplementary appendix 1 and fig 3 ).

\section{Five year implant survival}

The five year implant survival of uncemented total hip replacements performed in 2006-11 was slightly inferior to those performed in 1995-99 and in 2000-05. The five year implant survival of cemented total hip replacements performed in 2006-11 was similar to those performed in 2000-05 and higher than those performed in 1995-99 (see supplementary appendix 2).

\section{Discussion}

The survival of cemented implants for total hip replacement was higher than that of uncemented implants in patients aged 65 years or older. The increased use of uncemented implants in this age group is not supported by these data.

\section{Strengths and limitations of this study}

The major strength of our study is the unique collaboration of four national registers to create a multinational database with a high number of patients and a long follow-up time. Furthermore, completeness and validity of data are high in the Nordic countries. The main weakness of this study is that the minimal dataset of the Nordic Arthroplasty Register Association includes only basic information common to all national registers. Our data do not include information on variables such as material used for articulation, patient reported outcome measures, patients' state of health or comorbidity, activity levels, outcomes on materials used, or surgical skills. The bearing surface might be an important confounder when studying the association between fixation type and risk of revision. Implant survival of uncemented total hip replacement models with the highest quality bearing surfaces may be noticeably higher than that of the uncemented group as a whole. However, we believe that the high number of implants in the current study makes the bias from bearing surfaces tolerable. Furthermore, implant survival may not be the only relevant outcome after total hip replacement. It has been suggested that mortality is higher in the population receiving cemented implants than in the population receiving uncemented implants. ${ }^{14}$ However, mortality was not assessed in the current study. In the future, analyses on mortality may be performed based on information from the Nordic Arthroplasty Register Association database.

\section{Comparison with other studies}

\section{Use of different implant fixation: time trend}

The proportion of total hip replacements using uncemented implants increased rapidly towards the end of the study period. From 2006 to 2010 the proportion of uncemented implants has also increased in several other countries with longer standing register data, such as England and Wales, Australia, Canada, and New Zealand. ${ }^{15}$ The proportion of uncemented total hip replacements was $44 \%$ in England and Wales, ${ }^{8}{ }^{14} 64 \%$ in Australia, ${ }^{9} 47 \%$ in New Zealand ${ }^{24}$ in 2011, and $82 \%$ in Canada $^{25}$ in 2010. The majority of total hip replacements in the United States are performed with uncemented implants (86\%). ${ }^{16}$ However, in New Zealand the proportion of total hip replacements using uncemented implants fell for the first time in years, from 52\% in 2010 to $47 \%$ in 2011, with corresponding increases in fully cemented and hybrid arthroplasties. ${ }^{24}$ Total hip replacements using hybrid implants are more common in England and Wales ${ }^{8}$ (18\% in 2011), New Zealand ${ }^{24}$ (39\% in 2011), and Australia ${ }^{9}$ (31\% in 2011) than in Nordic countries. The proportion of total hip replacements using hybrid implants is decreasing in Nordic countries according to these data, but not in Australia, ${ }^{9}$ England and Wales ${ }^{8}$ or New Zealand. ${ }^{24}$ The proportion of total hip replacements using reverse hybrid implants is increasing in the Nordic countries. In 2011 in England and Wales, 15\% of all total hip replacements using hybrid or reverse hybrid implants were reverse hybrids. ${ }^{8}$

\section{Implant survival}

The risk of revision with cemented implants decreased during the first six months after total hip replacement in all age groups compared with all other fixation types, mainly as a result of a few revision operations performed for periprosthetic fracture or early aseptic loosening when using cemented implants. Patients being considered for total hip arthroplasty should be informed of an increased early risk of revision using fixation methods other than cemented implants.

According to the current data the risk of revision from cemented implants was decreased compared with all other fixation types in patients aged 55 years or older. However, proportional hazard assumption was not fulfilled in our Cox analyses for the whole study period. The risk of revision from uncemented implants was increased compared with that of cemented implants in the oldest age groups in analysis of data from the National Joint Registry of England and Wales (56\% for 56-64 year old men, $54 \%$ for $56-64$ year old women, $73 \%$ for men aged $\geq 65$ years, $121 \%$ for women aged $\geq 65$ years) ${ }^{8}$ and in Australia ( $40 \%$ for both sexes aged $\geq 75$ years). ${ }^{9}$ In Australia the overall risk of revision from cemented implants was $48 \%$ higher than that of uncemented implants in patients aged 55 to 64 years, ${ }^{9}$ which is opposite to our findings. This difference may be caused by different implant choices and bearing surfaces in Europe and Australia. However, training and technical skills of orthopaedic 
surgeons may be as important to the survival of implants as the choice of implant. ${ }^{26}$ Also, there may be geographical variation in coping with the learning curve.

The overall risk of revision from hybrid implants was increased $48 \%$ compared with that of cemented implants in England and Wales ${ }^{8}$ for men aged more than 65 years and $43 \%$ for similarly aged women. In the age group 56 to 64 years the differences between hybrid and cemented implants were not significant. ${ }^{8}$ In Australia the overall risk of revision from cemented implants was increased $45 \%$ compared with that of hybrid implants in the age groups 55 to 64 years and $29 \%$ in the age group 65 to 74 years. ${ }^{9}$ In the oldest age group the difference between hybrid and cemented implants was not significant. ${ }^{9}$ The revision risk of hybrid implants was increased compared with that of cemented implants in all age groups in the current study. The relatively poor survival of the hybrid implants in our study may be related to choice of implant and type of polyethylene used for articulation. In Australia and England, Exeter hybrids are predominant and may skew the results towards better ones than ours. Furthermore, longer follow-up in our study captures more revisions related to wear and osteolysis and a higher proportion of implants with poorly performing polyethylenes. ${ }^{27}$ The use of reverse hybrid implants was suggested in the late 1990s as an alternative to fully uncemented implants in younger patients owing to the problem of wear of the conventional polyethylene liners. ${ }^{4}$ Nowadays, reverse hybrid implants seem to be used more as an alternative to fully cemented implants in more elderly patients. The survival of reverse hybrid implants in our study was inferior to that of the cemented implants in patients aged 65 years or older. This finding is in accordance with previous data reporting an increased risk of early periprosthetic fractures ${ }^{28}$ and infections using reverse hybrid implants. ${ }^{29}$

The increasing move towards using uncemented implants in Nordic countries has been certainly influenced by reports from experts in single centres with good outcomes. However, excellent implant survivorship has been reported for all kinds of fixation techniques. ${ }^{30}$ In our opinion, intense marketing of more expensive uncemented implants by industry has strongly influenced the current trend. Willingness of orthopaedic surgeons to adopt faster uncemented techniques with the ongoing intense marketing has been high. The inferior five year survival of uncemented implants for total hip replacements performed during 2006-11 compared with those performed during 1995-99 or 2000-05 does not support continuing this trend.

Because proportional hazard assumption was not fulfilled in our Cox analyses for the whole study period, we split the follow-up in to one year intervals, except that the first year was divided in to two periods. However, in a comparison of our data with that of other registers we used risk ratios for the whole interval from 1995 to 2011 . We acknowledge that the use of such risk estimates biases our results. However, proportional hazard assumption may not have been fulfilled in analyses of other national registers either. Owing to statistical issues interpretation of comparisons based on data derived from diverse national registers should be performed cautiously. Furthermore, registers have different strategies for presenting data, which may also be an obstacle to uniform interpretation of data on revision risks. ${ }^{15}$ Hazard ratios and revision rate per 100 component years are both used. ${ }^{8-24}$ The use of component years in reporting register results may be misleading since the type and incidence of complications varies over time. For example, during the first two postoperative years revisions due to dislocations and infections will prevail, but with longer follow-up there will be more revisions due to loosening. Also, age groups may be defined differently among registers. ${ }^{15} \mathrm{~A}$ worldwide database common to all national registers enabling direct comparison of hip replacements would noticeably increase the reliability of arthroplasty data.

Contributors: All authors were involved in the study design, analysis and interpretation of the data, and drafting and final approval of the manuscript. KTM is guarantor. All authors had full access to all of the data (including statistical reports and tables) in the study and can take responsibility for the integrity of the data and the accuracy of the data analysis.

Funding: This study was funded by a research grant from Turku University Hospital and a grant from the Orion-Farmos Research Foundation. These are non-profit organisations and with no role in the study. The researchers are totally independent of the funders.

Competing interests: All authors have completed the ICMJE uniform disclosure form at www.icmje.org/coi_disclosure.pdf (available on request from the corresponding author) and declare: JK has received grants outside the submitted work from Link Germany, Zimmer Europe, and Biomet; OF has received grants from Smith \& Nephew, Norway, and Orthomedic, Norway, outside the submitted work; $\mathrm{HM}$ has received grants from Link Germany, Zimmer Europe and USA, Biomet Europe and USA, MAKO USA, and DePuy outside the submitted work; no support from any organisation for the submitted work; no financial relationships with any organisations that might have an interest in the submitted work in the previous three years; and no other relationships or activities that could appear to have influenced the submitted work.

Ethical approval: This study was approved through each national registries own ethical process.

Data sharing: No additional data available.

Transparency: A statement that the lead author (the manuscript's guarantor) affirms that the manuscript is an honest, accurate, and transparent account of the study being reported; that no important aspects of the study have been omitted; and that any discrepancies from the study as planned (and, if relevant, registered) have been explained.

Benson K, Hartz A. A comparison of observational studies and randomized, controlled studies. N Engl J Med 2000;342:1878-86.

2 Concato J, Shah N, Horwitz RI. Randomized, controlled trials, observational studies, and the hierarchy of research designs. N Engl J Med 2000;342:1887-92.

3 Paavolainen P, Hämälainen M, Mustonen $\mathrm{H}$, Slatis P. Registration of arthroplasties in Finland. A nationwide prospective project. Acta Orthop Scand 1991;(Suppl):27-30.

4 Havelin LI, Engesaeter LB, Espehaug B, Furnes O, Lie SA, Vollset SE. The Norwegian Arthroplasty Register: 11 years and 73,000 arthroplasties. Acta Orthop Scand 2000;71:337-53.

5 Lucht U. The Danish Hip Arthroplasty Register. Acta Orthop Scand 2000;71:433-9.

6 Malchau H, Herberts P, Eisler T, Garellick G, Söderman P. The Swedish total hip replacement register. J Bone Joint Surg Am 2002;84(Suppl 2):2-20.

7 Havelin LI, Fenstad AM, Salomonsson R, Mehnert F, Furnes O, Overgaard S, et al. The Nordic Arthroplasty Register Association. A unique collaboration between 3 national hip arthroplasty registries with 280,201 THRs. Acta Orthop 2009;80:393-401.

8 National Joint Registry for England and Wales (NJR England-Wales). Ninth annual report 2011. www.njrcentre.org.uk

9 Australian Orthopaedic Association. National Joint Replacement Registry. Annual report 2012. https://aoanjrr.dmac.adelaide.edu.au

10 Swedish Hip Arthroplasty Register (SHAR). The annual report 2011. www.shpr.se

11 Norwegian Arthroplasty Register (NAR). The annual report 2010. http://nrlweb.inelse.net

12 Mäkelä K, Eskelinen A, Pulkkinen P, Paavolainen P, Remes V. Cemented total hip replacement for primary osteoarthritis in patients aged 55 years or older: results of the 12 most common cemented implants followed for 25 years in the Finnish Arthroplasty Register. J Bone Joint Surg Br 2008;90:1562-9.

13 Corbett KL, Losina E, Nti AA, Prokopetz JJZ, Katz JN. Population-based rates of revision of primary total hip arthroplasty: a systematic review. PLOS One 2010;5:e13520

14 McMinn DJW, Snell KIE, Daniel J, Treacy RBC, Pynsent PB, Riley RD. Mortality and implant revision rates of hip arthroplasty in patients with osteoarthritis: registry based cohort study. BMJ 2012;344:e3319.

15 Troelsen A, Malchau E, Sillesen N, Malchau H. A review of current fixation use and registry outcomes in total hip arthroplasty: the uncemented paradox. Clin Orthop Relat Res 2013:471:2052-9.

16 Huo MH, Dumont GD, Knight JR, Mont MA. What's new in total hip arthroplasty. J Bone Joint Surg Am 2011;93:1944-50.

17 Espehaug B, Furnes O, Havelin LI, Engesaeter LB, Vollset SE, Kindseth O. Registration completeness in the Norwegian Arthroplasty Register. Acta Orthop 2006;77:49-56.

18 Arthursson AJ, Furnes O, Espehaug B, Havelin LI, Söreide JA. Validation of data in the Norwegian Arthroplasty Register and the Norwegian Patient Register: 5,134 primary total hip arthroplasties and revisions operated at a single hospital between 1987 and 2003. Acta Orthop 2005;76:823-8 


\section{What is already known on this topic}

Cemented fixation has been the ideal method of total hip replacement in many countries

Uncemented implants have been largely used in Australia, the United States, and some European countries

\section{What this study adds}

In our multinational register study the survival of cemented implants for total hip replacements was higher than that of uncemented implants in patients aged 65 years or older

The proportion of total hip replacements performed with uncemented implants is rapidly increasing in Nordic countries but such use is not supported by the data

Because our dataset includes basic information common to all national registers, however, there is potential for residual confounding

19 Swedish Hip Arthroplasty register (SHAR). Annual yearbook 2011. www.shpr.se/

20 Danish Hip Arthroplasty Register (DHAR). Annual report 2011. www.dhr.dk/

21 Peltola M. National Institute for Health and Welfare. Personal communication, 2013.

22 Lie SA, Engesaeter LB, Havelin LI, Gjessing HK, Vollset SE. Dependency issues in surviva analyses of 55,782 primary hip replacements from 47,355 patients. Stat Med 2004;23:3227-40.

23 Ranstam J, Kärrholm J, Pulkkinen P, Mäkelä K, Espehaug B, Pedersen AB, et al. Statistical analysis of arthroplasty data II. Guidelines. Acta Orthop 2011;82:258-67.

24 The New Zealand Joint Registry. Thirteen year report: January 1999 to December 2011. www.cdhb.govt.nz

25 Canadian Joint Replacement Registry. Hip and knee replacements in Canada-2011 annual statistics. www.cihi.ca

26 Hamilton DF, Simpson AH, Howie CR, Porter DE. The role of the surgeon in the application of the scientific method to new orthopaedic devices. Surgeon 2013;11:117-9.

27 Hallan G, Dybvik E, Furnes O, Havelin LI. Metal-backed acetabular components with conventional polyethylene: a review of 9113 primary components with a follow-up of 20 years. J Bone Joint Surg Br 2010;92:196-201.

28 Thien T, Chatziagorou G, Garellick G, Furnes O, Havelin LI, Mäkelä K, et al. Periprosthetic fracture within 2 years after THR. Analysis of 437629 operations in the Nordic Arthroplasty Registry Association database. J Bone Joint Surg Am 2014 (in press).
29 Dale H, Fenstad AM, Hallan G, Havelin LI, Furnes O, Overgaard S, et al. Increasing risk of prosthetic joint infection after total hip arthroplasty. 2,778 revisions due to infection after 432,168 primary THAs in the Nordic Arthroplasty Register Association (NARA). Acta Orthop 2012;83:449-58.

30 Berry DJ, Harmsen WS, Cabanela ME, Morrey BF. Twenty-five year survivorship of two thousand consecutive primary Charnley total hip replacements: factors affecting survivorship of acetabular and femoral components. J Bone Joint Surg Am 2002;84:171-7.

31 Della Valle CJ, Mesko NW, Quigley L, Rosenberg AG, Jacobs JJ, Galante JO. Primary total hip arthroplasty with a porous-coated acetabular component: a concise follow-up, at a minimum of twenty years, of previous reports. J Bone Joint Surg Am 2009;91:1130-5.

\section{Cite this as: BMJ 2014;348:f7592}

This is an Open Access article distributed in accordance with the Creative Commons Attribution Non Commercial (CC BY-NC 3.0) license, which permits others to distribute, remix, adapt, build upon this work non-commercially, and license their derivative works on different terms, provided the original work is properly cited and the use is non-commercial. See: http://creativecommons.org/licenses/by-nc/3.0/. 


\section{Tables}

Table 1 | Personal characteristics and data on fixation type for total hip replacements by age group. Values are numbers (percentages) unless stated otherwise

\begin{tabular}{lcccc} 
& & \multicolumn{4}{c}{ Age groups (years) } \\
\cline { 3 - 5 } Characteristics & All & $\mathbf{5 5}$ to 64 & $\mathbf{6 5}$ to 74 & $\geq 75$ \\
No of total hip replacements & 347899 & $90723(26.1)$ & $139937(40.2)$ & $117239(33.7)$ \\
\hline Men & $137042(39.4)$ & $41469(45.7)$ & $56454(40.3)$ & $39119(33.4)$ \\
\hline Diagnosis: & & & & \\
\hline Primary osteoarthritis & $315216(90.6)$ & $78659(86.7)$ & $128562(91.9)$ & $107995(92.1)$ \\
\hline Non-traumatic femoral head necrosis & $7816(2.3)$ & $2056(2.3)$ & $2411(1.7)$ & $3349(2.9)$ \\
\hline Rheumatoid arthritis & $8705(2.5)$ & $2877(3.2)$ & $3704(2.6)$ & $2124(1.8)$ \\
\hline Paediatric hip disease & $7335(2.1)$ & $4043(4.5)$ & $2256(1.6)$ & $1036(0.9)$ \\
\hline Other & $8827(2.5)$ & $3088(3.4)$ & $3004(2.1)$ & $2735(2.3)$ \\
\hline Fixation: & & & & \\
\hline Cemented & $232603(66.9)$ & $40202(44.3)$ & $96346(68.9)$ & $96055(81.9)$ \\
\hline Uncemented & $71454(20.5)$ & $35092(38.7)$ & $26940(19.3)$ & $9422(8.0)$ \\
\hline Hybrid & $28215(8.1)$ & $7930(8.7)$ & $11272(8.1)$ & $9013(7.7)$ \\
\hline Reverse hybrid & $15627(4.5)$ & $7499(8.3)$ & $5379(3.8)$ & $2749(2.3)$ \\
\hline
\end{tabular}




\begin{tabular}{|c|c|c|c|c|c|c|}
\hline \multicolumn{7}{|c|}{ Table 2| Unadjusted Kaplan-Meier survival data at 10 and 15 years for total hip replacements, by fixation type } \\
\hline \multirow[b]{2}{*}{$\begin{array}{l}\text { Fixation type by age } \\
\text { group }\end{array}$} & \multirow[b]{2}{*}{$\begin{array}{l}\text { No of total hip } \\
\text { replacements }\end{array}$} & \multirow[b]{2}{*}{$\begin{array}{l}\text { No of } \\
\text { revisions }\end{array}$} & \multicolumn{2}{|c|}{10 year follow-up } & \multicolumn{2}{|c|}{15 year follow-up } \\
\hline & & & $\begin{array}{l}\text { No of patients at } \\
\text { risk }\end{array}$ & Survival (\%) $(95 \% \mathrm{Cl})$ & $\begin{array}{l}\text { No of patients at } \\
\text { risk }\end{array}$ & Survival (\%) $(95 \% \mathrm{Cl})$ \\
\hline \multicolumn{7}{|l|}{ Cemented: } \\
\hline $55-64$ & 40202 & 2832 & 13626 & 92.2 (91.8 to 92.5 ) & 2882 & 84.1 (83.4 to 84.8 ) \\
\hline $65-74$ & 96346 & 4799 & 29031 & $93.8(93.6$ to 94.0$)$ & 5389 & $89.3(88.9$ to 89.7$)$ \\
\hline$\geq 75$ & 96055 & 2775 & 17570 & $95.9(95.8$ to 96.1$)$ & 1831 & $93.9(93.5$ to 94.3$)$ \\
\hline \multicolumn{7}{|l|}{ Uncemented: } \\
\hline $55-64$ & 35092 & 1977 & 6102 & 91.8 (91.3 to 92.2 ) & 1308 & 82.8 (81.7 to 83.8 ) \\
\hline $65-74$ & 26940 & 1168 & 2885 & 92.9 (92.3 to 93.4$)$ & 454 & 87.8 (86.4 to 89.0$)$ \\
\hline$\geq 75$ & 9422 & 394 & 458 & 93.0 (91.8 to 94.0$)$ & 30 & - \\
\hline \multicolumn{7}{|l|}{ Hybrid: } \\
\hline $55-64$ & 7930 & 855 & 3685 & $90.0(89.2$ to 90.7$)$ & 741 & $80.7(79.2$ to 82.1$)$ \\
\hline $65-74$ & 11272 & 810 & 3738 & 91.6 (90.9 to 92.2 ) & 546 & 86.8 (85.6 to 87.9 ) \\
\hline$\geq 75$ & 9013 & 370 & 1328 & 93.9 (93.1 to 94.5$)$ & 109 & 91.6 (89.8 to 93.1$)$ \\
\hline \multicolumn{7}{|l|}{ Reverse hybrid: } \\
\hline $55-64$ & 7499 & 243 & 364 & 92.4 (90.9 to 93.7 ) & 19 & - \\
\hline $65-74$ & 5379 & 158 & 119 & 90.7 (87.3 to 93.2 ) & 7 & - \\
\hline$\geq 75$ & 2749 & 119 & 40 & $93.2(90.7 \text { to } 95.1)^{\star}$ & 3 & - \\
\hline
\end{tabular}




\begin{tabular}{|c|c|c|c|c|c|c|c|c|c|}
\hline \multirow[b]{2}{*}{$\begin{array}{l}\text { Fixation type by age } \\
\text { group }\end{array}$} & \multirow[b]{2}{*}{$\begin{array}{l}\text { No of total hip } \\
\text { replacements }\end{array}$} & \multirow[b]{2}{*}{$\begin{array}{c}\text { No of } \\
\text { revisions }\end{array}$} & \multicolumn{6}{|c|}{ Reasons for revision } & \multirow[b]{2}{*}{$\begin{array}{l}\text { Missing } \\
\text { data }\end{array}$} \\
\hline & & & Aseptic loosening & Deep infection & $\begin{array}{l}\text { Periprosthetic femoral } \\
\text { fracture }\end{array}$ & Dislocation & Pain & Other & \\
\hline \multicolumn{10}{|l|}{ Cemented: } \\
\hline $55-64$ & 40202 & 204 & $8(4)$ & $63(31)$ & $9(4)$ & $100(49)$ & 0 & $24(12)$ & 0 \\
\hline $65-74$ & 96346 & 586 & $34(6)$ & $192(33)$ & $20(3)$ & $300(51)$ & 4 & $36(6)$ & 0 \\
\hline$\geq 75$ & 96055 & 745 & $46(6)$ & $277(37)$ & $28(4)$ & $335(45)$ & 4 & $55(7)$ & 0 \\
\hline \multicolumn{10}{|l|}{ Uncemented: } \\
\hline $55-64$ & 35092 & 498 & $70(14)$ & $85(17)$ & $123(25)$ & $137(28)$ & 7 & $73(15)$ & 3 \\
\hline $65-74$ & 26940 & 472 & $70(15)$ & $81(17)$ & $137(29)$ & $130(28)$ & 2 & $50(11)$ & 2 \\
\hline$\geq 75$ & 9422 & 243 & $43(18)$ & $38(16)$ & $73(30)$ & $67(28)$ & 2 & $20(8)$ & 0 \\
\hline \multicolumn{10}{|l|}{ Hybrid: } \\
\hline $55-64$ & 7930 & 88 & $6(7)$ & $17(19)$ & $7(8)$ & $47(53)$ & 2 & $9(10)$ & 0 \\
\hline $65-74$ & 11272 & 132 & $12(9)$ & $30(23)$ & $6(5)$ & $75(57)$ & 0 & $9(7)$ & 0 \\
\hline$\geq 75$ & 9013 & 123 & $12(10)$ & $30(24)$ & $6(5)$ & $61(50)$ & 0 & $13(11)$ & 1 \\
\hline \multicolumn{10}{|l|}{ Reverse hybrid: } \\
\hline $55-64$ & 7499 & 65 & $11(17)$ & $15(23)$ & $18(28)$ & $14(22)$ & 0 & $7(11)$ & 0 \\
\hline $65-74$ & 5379 & 77 & $6(8)$ & $20(26)$ & $14(18)$ & $16(21)$ & 1 & $20(26)$ & 0 \\
\hline$\geq 75$ & 2749 & 84 & $8(10)$ & $29(35)$ & $18(21)$ & $15(18)$ & 1 & $12(14)$ & 1 \\
\hline
\end{tabular}




\section{Figures}

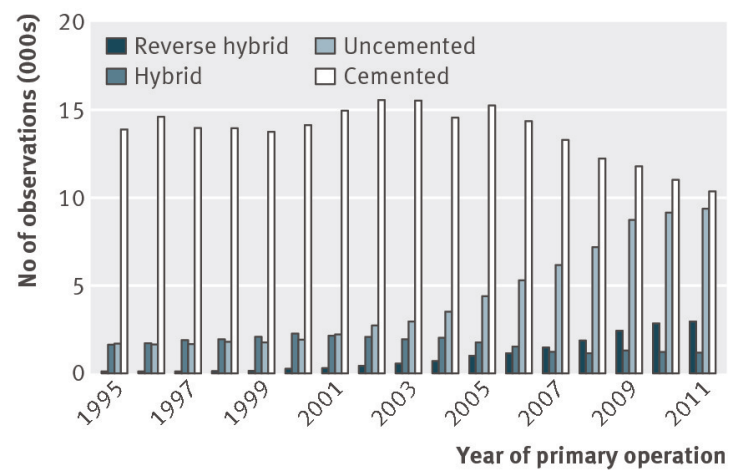

Fig 1 Yearly number of total hip replacements by fixation type in patients aged 55 years or older in Nordic Arthroplasty Register Association database
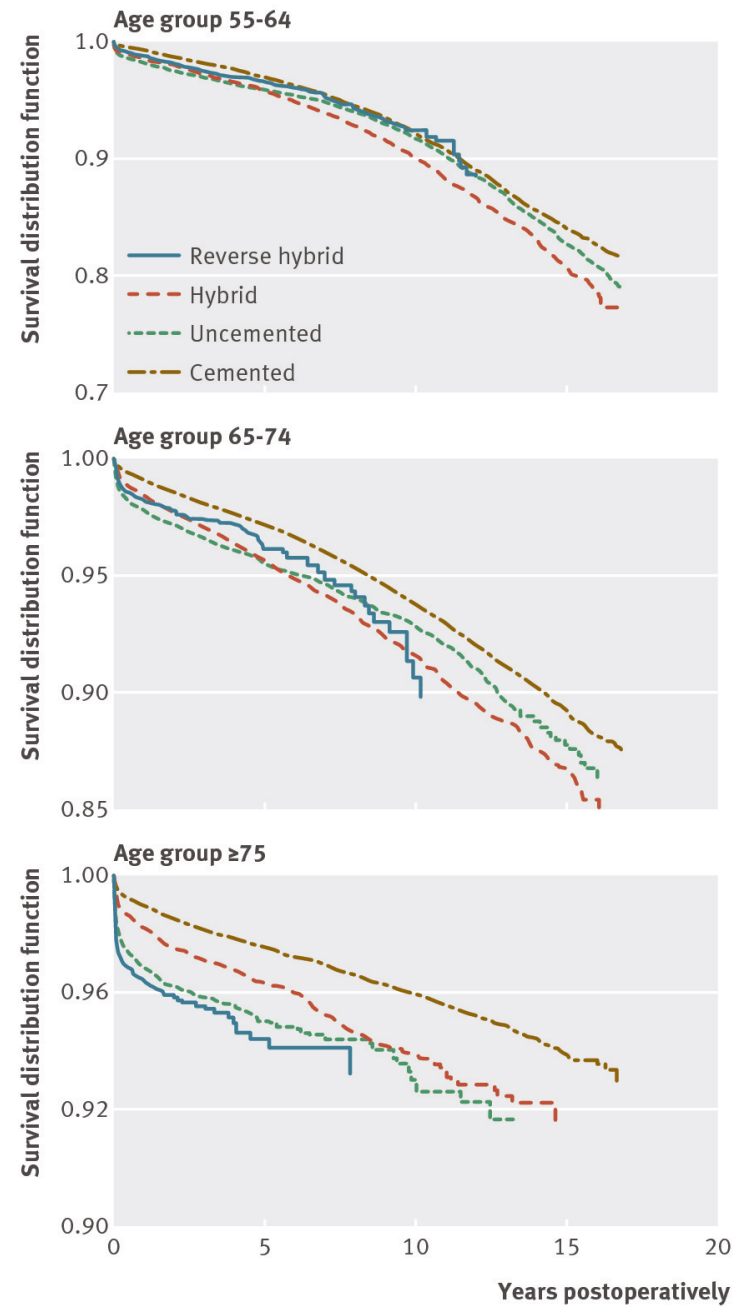

Fig 2 Kaplan-Meier implant survival curves for total hip replacements by fixation type and age groups 

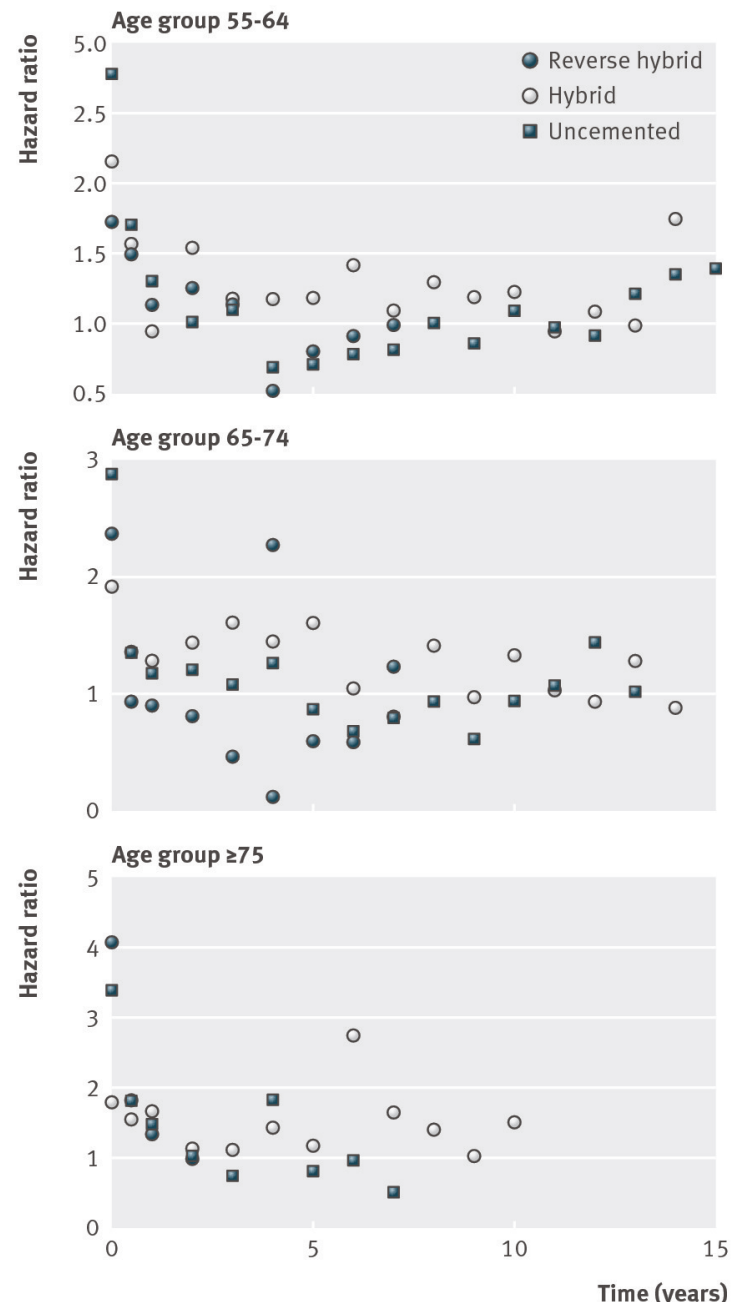

Fig 3 Hazard ratio for risk of revision of hybrid, reverse hybrid, and uncemented total hip replacements compared with cemented fixation in patients by age group. Hazard ratios are presented in one year periods, except for the first year, which has been divided into two periods. Hazard ratios are included for observations totaling at least 1000 at start of period 